\title{
Correction to: Peripheral nerve decompression in the upper limb in spinal cord injury: experiences at the National Spinal Injuries Centre, UK
}

Matthew Thomas, Alex Hinton, Anthony Heywood, Rebecca Shirley and James K. K. Chan

(c) The Author(s), under exclusive licence to International Spinal Cord Society 2021

Spinal Cord Series and Cases (2022)8:4; https://doi.org/10.1038/s41394-021-00468-5

Correction to: Spinal Cord Series and Cases https://doi.org/10.1038/ s41394-021-00423-4, published online 07 July 2021
In the original online version of this article the legends of Figs. 6 and 7 were swapped. The figures should have appeared as shown below. The original article has been corrected. 

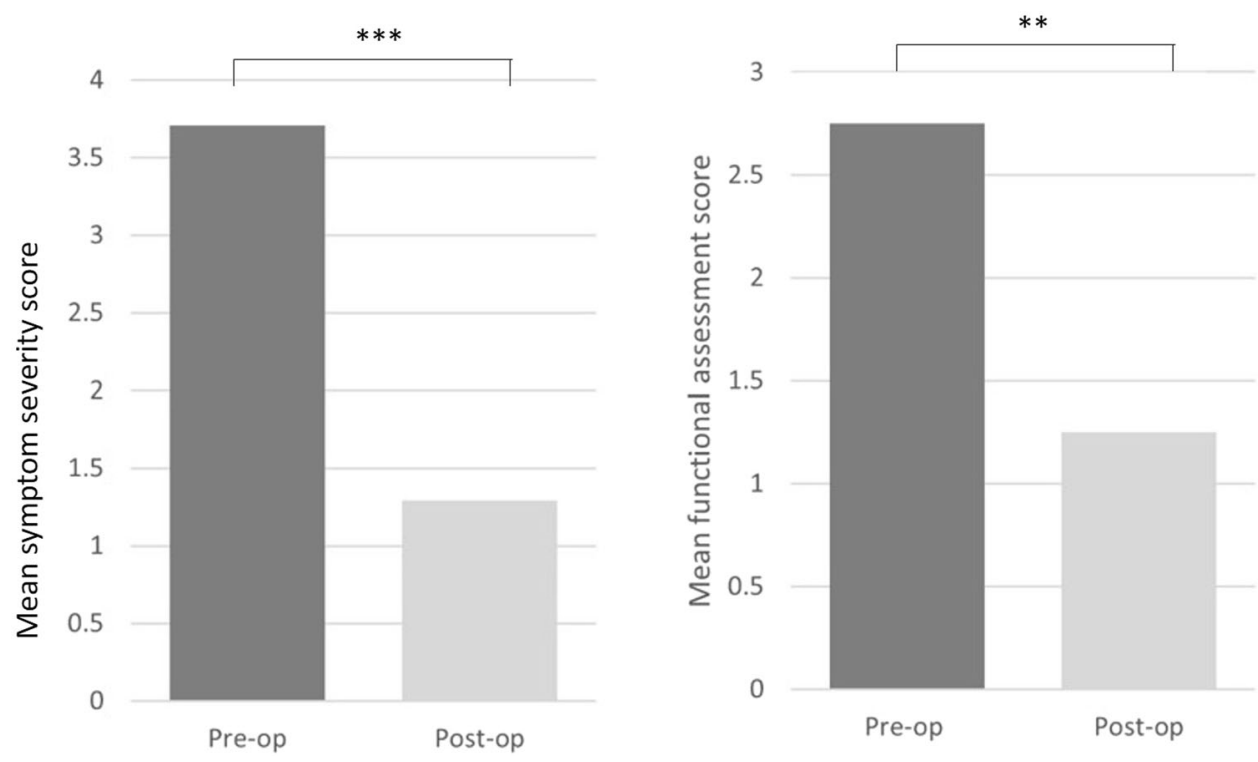

Fig. 6 Boston Carpal Tunnel Questionnaire Results (*** $p<0.001),\left({ }^{* *} p<0.01\right)$.

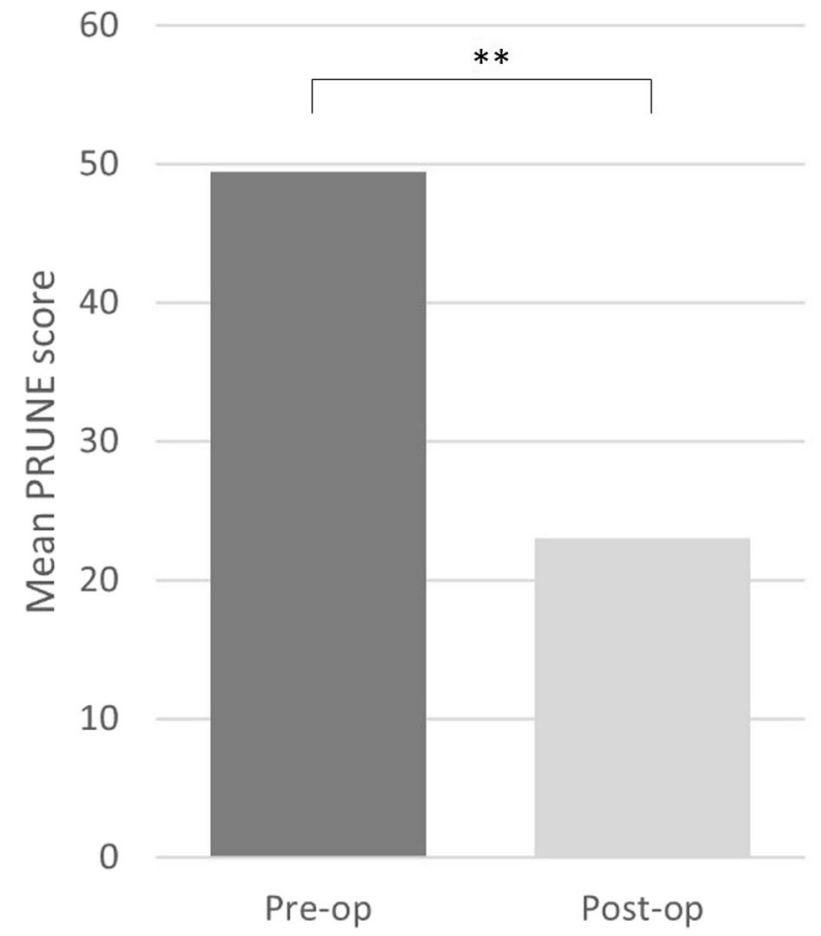

Fig. 7 Patient Reported Ulnar Nerve Evaluation Questionnaire (PRUNE) results $\left({ }^{* *} p<0.01\right)$. 